\title{
A Concise Review Encircling Lead Free Porous Piezoelectric Ceramics
}

\author{
E.D. Pinheiro AND T. Deivarajan* \\ Department of Ceramic Technology, Alagappa College of Technology, Anna University, \\ Chennai, Tamil Nadu, 600025, India
}

(Received July 31, 2019; in final form August 9, 2019)

\begin{abstract}
Lead free porous piezoelectric ceramics have been the motivation behind research by numerous scientists in perspective of environmental friendly, less dense, wide performance advantages over monolithic and polymer piezoelectric materials with enhanced figure of merit. In this review, a collective entity regarding the processing of porous piezoelectric compounds by various methods, lead free piezoelectric families like $\mathrm{BaTiO}_{3}(\mathrm{BT})$, $\mathrm{Ba}_{1-x} \mathrm{Ca}_{x} \mathrm{Ti}_{1-y} \mathrm{Zr}_{y} \mathrm{O}_{3}$ (BCZT), ( $\left.\mathrm{Bi}_{0.5} \mathrm{Na}_{0.5}\right) \mathrm{TiO}_{3}(\mathrm{BNT}),\left(\mathrm{K}_{0.5} \mathrm{Na}_{0.5}\right) \mathrm{NbO}_{3}(\mathrm{KNN})$ and their solid solutions are reported. Porosity configuration, pore forming agents, and various applications in porous lead free piezoelectric ceramic have also been discussed. This review herein has discussed in terms of the tendency to work with lead free porous piezoelectric ceramics.
\end{abstract}

DOI: 10.12693/APhysPolA.136.555

PACS/topics: porous ceramics, piezoelectricity, lead free, smart material

\section{Introduction}

Active (smart) materials are those which react to an incentive by changing its property, i.e. they expand or get deformed under temperature, pressure, or electromagnetic field. Active materials are used in integrating devices and structures which are capable of behaving according to the external conditions. Some of the widely used active materials are thermal materials (thermochromic, thermoelectric), mechanical materials (shape memory alloys and polymers, thermoelastic), magnetic materials (magnetoelastic, magnetoresistive, magnetooptic, ferrofluids, ferromagnetic shape memory alloys, etc.), electric materials (photoelectric, piezoelectric materials) [1] (see Fig. 1).

Piezoelectric materials have been an important timehonoured active materials because of their wide bandwidth, quick electromechanical response, low power assumption, high generative forces, ease of fabrication, survival in severe conditions, flexibility to be formed into various shapes, large dielectric constants, and high coupling coefficients $[2,3]$. Piezoelectric materials consist of multiple positive and negative interlocking domains which are symmetrical within the material making it to be neutral. When the materials are subjected to stress, its symmetry is slightly broken resulting in voltage generation and this effect is called direct piezoelectric effect. In another case when the voltage is applied to a material it gets deformed and this effect is called inverse or converse piezoelectric effect [4]. Piezoelectric effect has been made use of in variety of practical devices such as microphones, phonograph pickups, wave

*corresponding author; e-mail: muhil.ceramics@gmail.com

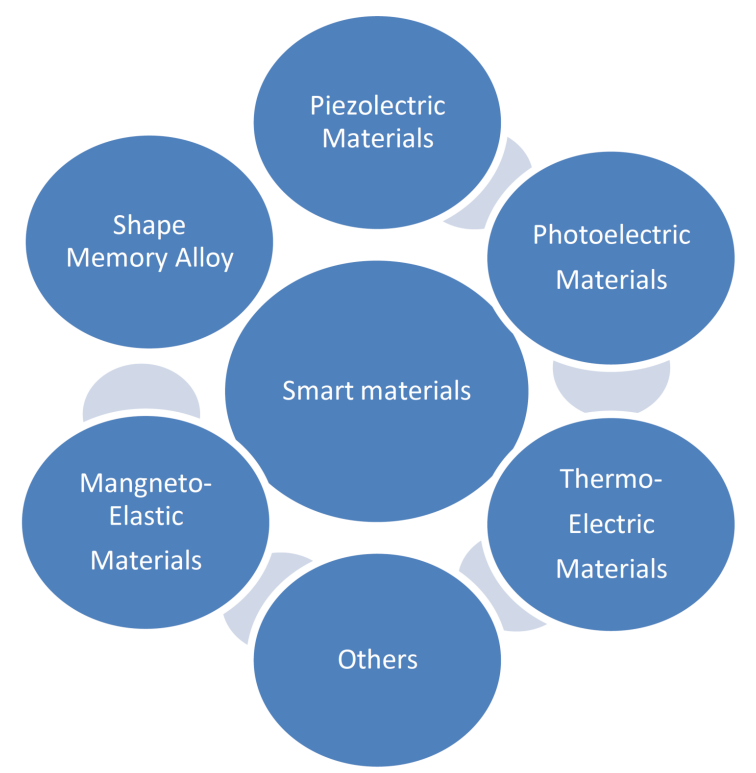

Fig. 1. Categories of smart materials.

filters in telephone-communications systems, sensors, actuators, energy harvesters etc., and for scientific instruments like microscopes [5].

Piezoelectric materials have been divided into two main streams: crystals and ceramics. The ceramics which are polycrystalline, have several qualities over crystals such as higher sensitivity and ease of fabrication into a variety of shapes and sizes. In crystals, there are limitations such as their susceptibility to moisture, high cost, difficulty to obtain proper orientation or chemical stoichiometry $[6,7]$. Piezoelectricity is an innate attribute in ceramic materials, where ultrahigh piezoelectric responses are realized in compositions at the morphotropic phase boundary (MPB) [8]. The MPB 
describes the boundary that separates regions of different symmetries and can be crossed through a change in composition [9]. This effect is related with the electric dipoles present within these materials. These dipoles together form regions called the Weiss domains, each differing from its neighbor only in the direction of orientation by default (i.e. their net polarization is zero). When the polycrystalline material is under stress, these domains change their orientation towards a direction that reduces the overall electrical or mechanical energy stored in the domain. This change of orientation direction from its former one is not sufficient to bring a change in the net polarization, hence the piezoelectric effect exhibited by the material will be negligible. Therefore, it is necessary to induce the piezoelectric effect in these materials by poling in the initial state to bring a significant change in the net polarization. Poling is a process of generating net remnant polarization in the material by applying sufficiently high electric field across the material below its Curie temperature. The Curie temperature is defined as the temperature at which the material nature gets converted to a non-piezoelectric from piezoelectric form. When an electric field is applied to a polycrystalline material, domains orient themselves in the direction of the applied field, the material in this state possesses maximum polarization [10, 11]. Polarized piezoelectric materials are characterized by several coefficients. These parameters are related to both direction of the applied stress, electric field, etc. and to the directions perpendicular to these. Due to this analogy, the parameters are generally given two subscript indices which refer to the direction of the two related quantities (e.g. stress and strain for elasticity, displacement, and electric field for permittivity). Since the piezoelectric material is anisotropic, the corresponding physical quantities are described by tensors [12]. The piezoelectric coefficients are therefore indexed accordingly [13-15].

- Piezoelectric strain constant, $d$ : This constant is related to the mechanical strain produced by an applied electric field, it is otherwise termed as $d$ coefficient, e.g. $d_{33}$ is the induced strain in direction 3 per unit electric field applied in direction 3 .

- Piezoelectric voltage coefficient $g_{i j}$ : This constant is related to the electric field produced by a mechanical stressor otherwise defined as ratio of the electric field strength $E$ to the effective mechanical stress $T$. It is termed as voltage constant, or the $g$ coefficient, e.g. $g_{33}$ is the induced strain in direction 3 per unit electric displacement applied in direction 3 .

- Permittivity $\varepsilon$ : Relative dielectric constant or permittivity $\varepsilon$ is defined as ratio of absolute permittivity of a ceramic material and permittivity in vacuum $\left(\varepsilon=8.85 \times 10^{-12} \mathrm{~F} / \mathrm{m}\right)$, where absolute permittivity is the measure of polarizability in the electric field.
- Coupling factor $K$ : This constant is the measure of piezoelectric effect. This describes the ability of the piezoelectric material to convert electrical energy to mechanical energy and vice versa. The ratio of the converted stored energy of one kind (mechanical or electrical) to the input energy of the second kind (electrical or mechanical) is defined as the square of the coupling coefficient.

Piezoelectric ceramics, solid solutions of ferroelectric composition are prepared by the synthesis (thermal treatment) of a mixture of different oxides, carbonates, and salts of metals and can be tailored according to the specific purpose requirements. The bases of advanced piezoelectric material relies on modified solid solutions with different composition and dopants. Lead zirconate titanate $\mathrm{Pb}\left(\mathrm{Zr}_{x} \mathrm{Ti}_{1-x}\right) \mathrm{O}_{3}$ (PZT), ceramic material, has superior piezoelectric properties and has wide possibilities for modifying its structure and properties by numerous dopants. They have found widespread applications in sensors, transducers, actuators, and electronic components $[16,17]$. In today's era, the most successful piezoelectric ceramics are based on lead based systems such as lead zirconate and lead titanate (PZT). Although, the major drawback of these lead based piezoelectric systems is its lead content, which is more than $60 \mathrm{wt} \%$. There are lots of environmental issues with utilization, recycling, and disposal of these lead-based materials as the toxic matter maintains itself for a long time in the environment [18]. The urge for materials that are benign to the environment and human health has paved the way for a new ceramic materials, i.e. leadfree materials, which have become the kingpin in today's roadmap for ceramics, particularly those with properties comparable to their lead-based counterparts. Both extensive and intensive research activities have been devoted in developing lead-free piezoelectric systems in response to the call for environmental protections for past several years [19]. In addition to being environmentally friendly, lead free piezoelectric systems are biocompatible, and suitable for high temperature operations. Lead free piezoelectric materials are classified based on their structure into:

- Bismuth layered structure

- Tungsten-bronze structure

- Pyrochlore structure

- Perovskite structure

Perovskite structure has received distinct attention because of its simple structure when compared to other structures and ease of preparation. It has a general formula of $\mathrm{ABX}_{3}$, where $\mathrm{A}$ and $\mathrm{B}$ are the two cations of different sizes, usually $\mathrm{A}$ larger than $\mathrm{B}$, and $\mathrm{X}$ is an anion that bonds the cations. The main advantage of perovskite structure is that, different anions and cations dopants can be substituted on both A and B sites 
without any modification in the overall structure [20]. Lead free base materials barium titanate (BT), modified bismuth sodium titanate (BNT), potassium sodium niobate $(\mathrm{KNN})$, and their derivatives having perovskite structure were discovered in the 1940s-1960s [21-23]. Lead free materials as single systems were unable to exhibit expected piezoelectric properties when compared with single system of lead based counterparts. Therefore they are modified and doped accordingly in order to get extraordinary piezoelectric properties. Widely used lead free systems with perovskite structure are discussed below.

\subsection{Lead free systems with perovskite structure}

\subsubsection{Barium titanate $\mathrm{BaTiO}_{3}$ (BT)}

Barium titanate was one of the foremost piezoelectric materials, developed in the 1940s and 1950s [24-26]. $\mathrm{BaTiO}_{3}$ is a well-known fundamental ferroelectric strong candidate for field induced piezoelectric transducers having high dielectric constant, low loss characteristics, low Curie temperature, large polarizations, large permittivity, and the large induced strains achievable in these materials $[27,28]$. BT is also used as a potential candidate for capacitors even though it does not have a very high piezoelectric constant [29]. However the overall usefulness of BT have been limited as the working temperature range of BT ceramic had been narrowed for actual piezoelectric applications due to low Curie temperature $\left(T_{\mathrm{C}}=120^{\circ} \mathrm{C}\right)$. In lead free solid solution systems BT is often used as other lead-free compounds to improve the system's Curie temperature and to exhibit piezoelectric properties near MPB. Dopants like $\mathrm{Nb}_{2} \mathrm{O}_{5}$, $\mathrm{CeO}_{2}$, etc. were added and also binary and ternary system of BT based ceramics such as KBT-KNN-NBT, NBT-BT, KNN-BT, KBT-BT have been developed and investigated [30-33].

\subsubsection{Bismuth sodium titanate $\left(\mathrm{Bi}_{0.5} \mathrm{Na}_{0.5}\right) \mathrm{TiO}_{3}$ (BNT)}

Bismuth sodium titanate (BNT) with a rhombohedral perovskite structure have been studied for a long time as a promising alternative to lead based counterparts, having relatively high Curie temperature $\left(T_{\mathrm{C}}=320^{\circ} \mathrm{C}\right)$ and piezoelectric constant of $73 \mathrm{pC} / \mathrm{N}$ [34]. BNT has certain drawbacks such as it has high coercive field and high conductivity which cause difficulties in the poling process and quite low piezoelectric properties for pure BNT [35]. To overcome these drawbacks, different dopants are added as well modifications in the solid solution composition have been done to the BNT systems. Among the BNT-based lead-free piezoelectric systems, the binary systems of BNT-BKT and BNT-BT have obtained the most extensive investigation because they have exhibited extraordinary piezoelectric performance near the rhombohedral and tetragonal MPB. In addition, BNT-based compositions modified with $\left(\mathrm{Bi}_{0.5} \mathrm{Li}_{0.5}\right) \mathrm{TiO}_{3}, \mathrm{Ba}\left(\mathrm{Cu}_{0.5} \mathrm{~W}_{0.5}\right) \mathrm{O}_{3}, \mathrm{NaNbO}_{3}$, and $\mathrm{Er}_{2} \mathrm{O}_{3}$ have also been reported $[32,33]$.

\subsubsection{Bismuth potassium titanate}

$\left(\mathrm{Bi}_{0.5} \mathrm{~K}_{0.5}\right) \mathrm{TiO}_{3}(\mathrm{BKT})$

Discovery of BKT was done in 20th century. It has tetragonal symmetry at room temperature, relatively high $T_{c}$ of $380^{\circ} \mathrm{C}$, and shows better dielectric response and piezoelectric response than BNT. But BKT has been investigated much less than BNT material because of its drawback to prepare high-dense ceramics. These materials even face difficulty in poling due to low density and formation of secondary phases at high temperature poling. Sintering aids have been utilized in these materials to improve its density, such as processing of BKT with excess bismuth oxide, which improved the piezoelectric and ferroelectric properties of the material (e.g., $d_{33}=101 \mathrm{pC} / \mathrm{N}$ ) [36].

\subsubsection{Barium calcium zirconate titanate} $B a_{1-x} C a_{x} T i_{1-y} Z r_{y} O_{3}$ (BCZT)

Variety of $\mathrm{BaTiO}_{3}$-based solid solutions have been developed to enhance the piezoelectric and dielectric properties with different $\mathrm{A}$-site and $\mathrm{B}$-site dopants (where, typically $\mathrm{A}=\mathrm{Ca}, \mathrm{Sr}, \mathrm{La} ; \mathrm{B}=\mathrm{Nb}, \mathrm{Ta}, \mathrm{Zr}$ ). Specially formulated $\mathrm{BCZT} \mathrm{Ba}_{1-x} \mathrm{Ca}_{x} \mathrm{Ti}_{1-y} \mathrm{Zr}_{y} \mathrm{O}_{3}$ has been the focus of numerous publications after a high piezoelectric coefficient $\left(d_{33}=620 \mathrm{pC} / \mathrm{N}\right)$ was reported for $\mathrm{Ba}_{0.85} \mathrm{Ca}_{0.15} \mathrm{Ti}_{0.90} \mathrm{Zr}_{0.10} \mathrm{O}_{3}$ [37]. $\mathrm{BCZT}$ is a good candidate for a variety of applications, such as multilayer ceramic capacitors (MLCC), piezoelectric actuators, and positive temperature coefficient resistors (PTCR), due to its excellent dielectric, ferroelectric, and piezoelectric properties. Moreover, its properties can be controlled by varying the $\mathrm{Ba} / \mathrm{Ca}$ and $\mathrm{Zr} / \mathrm{Ti}$ proportions.

\subsubsection{Potassium sodium niobate $\mathrm{K}_{x} \mathrm{Na}_{1-x} \mathrm{NBO}_{3}$ (KNN)}

The pioneering works on $\mathrm{KNbO}_{3}-\mathrm{NaNbO}_{3}$ solid solution were carried out in the mid-50s. KNN is a specific composition resembling the PZT system having a complete solid solution of antiferroelectric $\mathrm{NaNbO}_{3}$ and ferroelectric $\mathrm{KNbO}_{3}$, in equal proportion which is close to the MPB between two orthorhombic phases and has high electromechanical coupling. Furthermore, it has been reported that doping of $\mathrm{Li}, \mathrm{Ta}$, and $\mathrm{Sb}$, leads to further elevation of the piezoelectricity. $\mathrm{KNN}$ is a solid solution of $\mathrm{KNbO}_{3}(\mathrm{KN})$ which possesses similar structures and phases to BT but higher phase transition temperatures. KNN has been a potential system among other lead free system because of its relatively high piezoelectric performance. The highest piezoelectric strain coefficient $d_{33}$ of $416 \mathrm{pC} / \mathrm{N}$, was achieved by both composition and structurally modifying this material [38].

\subsection{Porous piezoelectric ceramics}

Piezoelectric ceramics as a monolithic have high piezoelectric performances which have been used for applications in several branches, but they are hard and rigid for specific applications that requires flexibility and complicated shapes. To overcome this problem, composite materials are proposed. Generally speaking, a composite is considered to be any multiphase material that exhibits 
a combination of the properties of its phases. Piezoelectric composites are usually made up of secondary phases such as ceramics, metals, polymer, or pore, and primary phase of piezoelectric ceramic. Porous ceramics can be considered as a particular case of composite material. Porosity is generally reflected as a defect that causes a decrease in mechanical and piezoelectric properties of a piezoelectric material. But the introduction of tailored porosity in the hard piezoelectric ceramic gives it an enhanced piezoelectric capability and optimum set of electro physical characteristics like high hydrostatic figure of merit (HFOM) and lower sound velocity, making these materials to exhibit reduced acoustic impedance and improved coupling with water and biological tissue [39]. These properties make them more suitable for underwater and medical applications like ultrasonic defectoscopes, medical diagnostic, therapeutic ultrasonic equipment, etc. [40-42]. Further, these materials can be operated in a wide temperature range. Studies of microstructures of porous piezoelectric active ceramic and composite materials have been carried out by only a few researchers [40-43].

Lead free porous piezoelectric ceramic recently has been playing a vital role for various engineering applications as they can be designed as a functionally graded material. This review paper gives the importance in working with lead free porous piezoelectric ceramics. The synthesis and processing of porous piezoelectric ceramics and their properties which are influenced by porosity configuration have been deliberated. Several applications of porous piezoelectric ceramic have also been discussed here.

\section{Porous piezoelectric ceramics processing}

Materials having well controlled porosity exhibits properties and features which are generally not achieved by their conventional dense counterparts [44]. The two classes of porous ceramics are reticulate ceramics and foam ceramics. Interconnected voids surrounded by a web of ceramic are seen in the reticulate ceramics. The latter has closed voids within a continuous ceramic matrix [45]. Porous ceramics of open pores has substantial strength, moderate thermal conductivity, gas permeability, good thermal resistance. Ceramics of closed pores has high porosity, increased strength, decreased thermal conductivity, low thermal resistance. The connectivity nomenclature of piezoelectric composite with pores as the secondary inactive phases are $(0-$ $0),(0-1),(0-2),(0-3),(1-1),(1-2),(1-3),(2-2),(2-3)$, and $(3-3)$, where the first digit refers to the number of dimensions of connectivity for the active phase (piezoelectric ceramic) while the second digit refers to the inactive phase (pores) [46]. In porous piezoelectric ceramics, changes in open and closed porosity, pore size distribution, and pore morphology can have a major effect on a material's properties. The processing routes used for preparation of porous material have influence over these microstructural features. In addition to the conventional solid state reaction route, various chemical routes have been developed for obtaining porous piezoelectric ceramics.

The methods for porous ceramic processing include basic approaches like subtractive and additive processes. In the former processes density of the material is reduced through the addition of pore forming agents as resulting porous material with controlled porosity is formed. In the latter approach, composite piezoelectric material with optimized electromechanical response is formed by addition of two or more constituents [47, 48]. Some of the methods for processing porous ceramics include replica techniques (e.g., sponges for 3-3 composites), sacrificial template methods (either synthetic such as PMMA or natural such as wax, etc.) [49]. By varying the sintering temperature certain degree of porosity can be obtained with respect to the dense ceramic, but for higher degree of porosity one of the mentioned methods are preferred. The methods used in several works for processing porous piezoelectric ceramics are discussed in the following section.

\subsection{Replica method}

Replica method, reported in the 1960s, is the first method deliberately used for the production of macroporous ceramics with pore diameter greater than $50 \mu \mathrm{m}$. In this method, ceramic material is removed from the cellular structure (sponge) by controlled thermal treatments in order to produce a macroporous ceramic. Porous structure obtained from the sponge replica method can generate a total open porosity level within highly interconnected pores. The disadvantages of this technique lie in the development of the struts in reticulated structure during pyrolysis of the polymeric template which lies as a demerit to this technique as the mechanical of the porous material gets significantly weakened. The technique also requires several steps, which lengthen its duration and increase its cost [50-57]. Many synthetic and natural templates approaches have been used in replica method. Another approach of replica technique is the coral replica method. In this method porous materials are prepared by using coral as the natural template, mostly for the application of bone replacement, etc. $[58,59]$. Here coral is first impregnated with wax under vacuum and after the hardening of the wax, the impregnated sample is leached by strong acids to obtain the celluar structure of the template in the wax form [60]. This method has been used to produce macroporous PZT ceramics with tailored piezoelectric properties $[61,62]$. In this approach the PZT slip was filled into the cellular structure, which was then sintered for densifying PZT. The obtained PZT samples had large pores which were filled with epoxy resins and polymers for 3-3 connectivity. However, this method is not easy to scale up and so other methods for creating porous ceramics have been devised. 


\subsection{Sacrificial method}

In sacrificial method, ceramic raw materials are mixed with appropriate amount of sacrificial fugitives, which are then burned out or evaporated by sintering to form porous body. Open pores of different morphologies can be produced with this method. The most crucial step in this technique is the removal of the sacrificial phase that can be done by pyrolysis, evaporation, or sublimation. These processes might involve the release of an excessive amount of gases and must be carried out at sufficiently slow rates in order to avoid cracking of the cellular structure. This method is time consuming, hence pore agents such as oil, water, naphthalene can be used for quick evaporation. There are less work reported on preparation of porous piezoelectric ceramics by this method due to mingling of the fugitives with the material which results in unexpected end product, excess timing, etc.

\subsection{Freeze casting method}

Freeze-casting, also known as ice-templating, is an attractive shaping method for the fabrication of highly organized porous structures. In this technique, the ceramic slurries containing freeze sensitive liquids vehicles (water or silica-sol) are poured into a nonporous mould, which would be frozen under extremely cold temperatures. After complete freezing, the samples are thermally treated to melt or sublimate the liquid vehicles and then the sample is dried for the formation of rigid bodies. The freezing agent acts as temporary binder. After drying, the former green body will possess relatively high degree of overall porosity, with pore channels formed as the replica of liquid vehicle used in the slurry. In this method, during freezing, certain ceramic particle in liquid vehicle solidifies as dendrites, as these are rejected because they are not soluble in ice formed due to freezing. The dendrite network and particle network are interlaced in three-dimensional space, which allows the pore structure of the ceramics to be tightly controlled. To date, water [63, 64] and camphene [65-67] have been successfully used as freezing vehicles [68]. Porous PZT-PZN were fabricated using the camphenebased freeze-casting method. Owing to the unique freezing behavior of the ceramic/camphene slurry, it was possible to produce highly porous ceramics with welldefined pore channels, as well as dense PZT-PZN walls. The porous samples had high HFOM values as the permittivity and $d_{33}$ value decreased due to $82 \%$ of porosity [67]. The freeze-casting route has many advantages such as fast manufacturing cycle, no drying cracks, essentially zero-shrinkage, and no troublesome binder burnout process.

\subsection{Burned out polymer spheres (BURPS) method}

The BURPS process involves formation of 3-3 structures with relative ease and low cost. In this process a pore-forming agent (PFA) will be incorporated along with ceramic powder before the pressing stage and during the sintering process the pore agent will be burned out leaving pores [69]. Various pore formers, such as poly (methyl methacrylate) (PMMA), poly(ethylene oxide) (PEO), self-raising flour, dextrin, and poly(vinyl alcohol) (PVA) has been used for this process [70-72]. These pore formers size has an effect on pore size developed in the porous structure. Porous PZT samples were processed by this method using different pore formers such as PVC, PMMA, and PEO with different weight ratios. The microstructure revealed a (3-3) connectivity in the porous structure. The pore forming agent PMMA exhibited a greater (3-3) connectivity in porous specimens when compared with other pore formers. The pore size of PMMA and PEO microstructure varies, but final properties were more or less similar [73]. Sintering profiles can be adjusted to include a dwell stage according to the required temperature at which the PFA sublimes. Disadvantage of the BURPS process is that it often suffers from poor control over the pore structure. Defects on the sintered samples and rifting of the interconnection between the pores often occurs due to intrusive burning of the PFA which may reduce both mechanical and piezoelectric properties of the porous piezoelectric ceramics.

\subsection{Gel casting}

Gel-casting is a favorable method to fabricate porous ceramics, which involves different method within it like foaming, replica method, or even the addition of a sacrificial phase [74]. Gel-casting is a near-net-shape forming method to produce tough complex shaped ceramic parts with high homogeneity, good strength and mechanical property with ease. This process involves the dispersion of a ceramic powder into a monomer and cross linker solution followed by casting of this suspension into a nonporous mould. In this method, the amount of organic used is less than other techniques which reduces the pyrolysis step prior to sintering and allows for the formation of porous ceramics with controlled degree of pore interconnectivity [75]. After gel formation, gel-cast green materials can be easily demoulded and dried in controlled conditions. Porous lead based PZT ceramics prepared by this method showed high quality and homogeneous ceramics parts with good piezoelectric properties were obtained [76]. The formation of porous zirconia by direct gel-casting method are used for dental application and highly porous ceramics are used in medical application such as bone repair implants.

\subsection{Solid freeform fabrication (SFF) or fused deposition method (FDM)}

3D printing technology has been referred to different names, such as fused deposition technology (FDM) or solid freeform fabrication (SFF). It is commonly referred to as desktop manufacturing or automated additive fabrication, which have become an important tool for manufacturers for production and design of prototypes. This process fabricates three-dimensional porous 
ceramic preforms from ceramic powders and preceramic polymers. In this process ceramic slurry is mixed with a thermoplastic binder to make the filament, which is printed to form the desired structure. The green structure is then sintered to remove the thermoplastic binder and densify the ceramic phase. Also, the use of 3D printing in combination with electrospinning technology can be used to form structures with nanoscale piezoelectric filaments. This method has been used for the development of porous piezoceramic PZT thick films, where the thick film was deposited on a substrate by screen printing. The porosity of the thick films was achieved by reducing the sintering temperature when compared to the bulk ceramic and the shrinkage rate was decreased by the addition of additives to the PZT sample [77].

\subsection{Emulsions template method or particle stabilized emulsion method}

An innovative methodology encompassing the use of combination with sol-gel reactants and surfactants to fabricate macroporous structures from mono disperse oil droplets obtained by fractionation is the emulsion template method [78]. Highly porous PZT samples were prepared by particle-stabilized foams via gel-casting. For this preparation, a slurry containing PZT powders, water, and monomer was prepared by milling. To this slurry valeric acid was added to modify the PZT particles and its $\mathrm{pH}$ was maintained to 5 by addition of $3 \mathrm{M} \mathrm{HCl}$ aqueous solution. The slurry was foamed with help of household mixer with addition of catalyst and initiator leading to the polymerization of monomer. The wet foam was then dried and sintered. The obtained porous sample had increased grain size and piezoelectric properties [79]. This method can be tuned to produce highly controlled self-assembled porosity of $90 \%$. This methods has advantages over other methods for the production of macroporous material because other techniques are not readily adapted to produce a wide variety of porous materials.

\section{Porous piezoelectric ceramic configuration and its properties}

Porous piezoelectric ceramic has been formulated as a functionally graded material (FGM) to meet the need of a high response, good compatibility with the investigated media by a porous material [80]. In these multiphase materials the distribution of the electric field strength and mechanical stresses, as well as the dielectric, elastic, mechanical properties, and their constants are not only influenced by the individual phases, but also by their interconnection of pores, pore distribution, pore volume [81]. Some of the parameters which influence the porous piezoelectric ceramics are discussed below.

\subsection{Pore forming agents (PFA)}

The pore forming agents are generally classified into synthetic organic matters (polymer beads, organic fibers, etc.), natural organic matters (potato starch, cellulose, cotton, etc.) metallic and inorganic matters (nickel, carbon, fly ash, glass particles, etc.) and liquid (water, gel, emulsions, etc.). Certain features of the porous structure include total, open, and sealed porosity, permeability, pore distribution by sizes, and specific surface area. The most significant structural parameters are porosity percentage and pore size. The pore size and porosity are mainly determined by the content and size of the pore formers. In PZT piezoelectric ceramic, when pore formers such as dextrin and PMMA were incorporated at various wt\%, from the microstructure studies it was revealed that with an increase in the content of pore formers, the porosity of sintered ceramics increased, whereas the pore size of porous PMMA ceramics were larger than porous dextrin ceramics [82]. As porosity volume fraction increases in a material, the interconnection between the pores increases with clear pore channel and their mean pore size also increases. For porous ceramic processing, PFA must be selected in the manner that it does not affect the final product such as cracking. In ceramics samples, where pore agents of relatively high stiffness materials were used, cracking occurred. Such as in samples where PMMA was used as the pore former cracking of the sample occurred as the relatively high stiffness PFA, led to spring back after pressure has been released in the pressing stage, resulting in cracks perpendicular to the pressing direction.

\subsection{Porosity configuration}

The porosity percentage has a great influence on the properties of the porous material. In the processing of porous lead based piezoelectric material it was perceived that an optimized combination of micro-, meso-, and macroporosity in $\mathrm{PbNb}_{2} \mathrm{O}_{6}$ porous ceramics prevents excessive crystalline growth and cracking. For $\mathrm{PbTiO}_{3}$ porous ceramics, the mixture of macroand mesoporosity prevents ceramic cracking and destruction on grain boundaries. It was also shown that the porous ceramics technology results in increased piezoelectric anisotropy, removal of internal mechanical stress, increased mechanical durability, prevention of cracking, and finally of stability in time elements with excellent and reproducible properties for such technologically difficult ceramics as lead titanate and lead metaniobate [83]. It was revealed that as the porosity percentage increases in a piezoelectric material its impedance reaches values closer to water or air. Also, it transverse piezoelectric coefficient $\left(d_{31}\right)$ decreases with increase in hydrostatic strain coefficient. Therefore, higher electrical charges will be generated for porous piezoelectric ceramics used as hydrophones [84].

\subsection{Porous piezoelectric ceramic properties}

Porous piezoelectric materials have favorable properties than the dense counterparts in many applications such as increase of the FOM by partial decoupling between transverse and longitudinal effects and grading 
of transfer of acoustical energy to water or biological tissues, improved as a consequence of a lower acoustical impedance $(Z)$. As the porous ceramic is less dense than its bulk counterpart, its acoustic impedance is lower, resulting in better impedance matching with water or tissue. As the acoustic impedance of the material is proportional to its relative density and the velocity of sound within it, a higher porosity would be expected to lead to a reduction in the acoustic impedance, which would minimize the sound energy reflected at the interface between the porous sample PZT-PZN ceramics and the media [85]. Porous piezoelectric ceramics such as lead zirconate titanate (PZT) offer significant improvements over solid piezoelectric ceramics in many piezoelectric transducer design figures of merit. With increasing porosity in piezoelectric ceramics, there is a reduction in the dielectric constant whereas the hydrostatic figure of merit $d_{h}, g_{h}$ increases significantly, for low-frequency underwater applications and medical diagnostic devices. These outstanding properties of porous piezoelectric ceramics seems to be surprising in contrast to the performance of typical dense ceramics whose inbuilt porosity results in loss of stiffness and strength. It was reported that porous piezoelectric ceramics exhibited gradual increase of piezoelectric charge coefficient $d_{33}$ factor with increasing porosity. Thus, increased porosity makes the material softer making it suitable for light weight applications such as sensors [86]. In porous material figuresof-merit improved markedly due to the reduced relative permittivity, although most of the physical properties are ruined by the presence of porosity porous ferroelectric ceramics, and therefore, are very promising materials for a number of applications. Some of the properties imparted due to porosity in a porous piezoelectric ceramics are as below:

- Lower acoustic impedance

- Lower density

- Better impedance matching with liquid medium

- High figure of merit

- High permeability rate

\section{Application of porous piezoelectric ceramics}

A significant advantage in porous piezoelectric ceramics is that numerous properties can be altered by introducing porosity for required applications. Lead free porous ceramics are being used in applications like acoustic transducers, humidity sensors, medical devices etc. At present, various porous products are manufactured for the purpose of decreasing thermal conductivity, increasing gas and liquid permeability, and increasing the inner surface of pore space for impregnation. Some of the widely used applications are listed in Table I and are discussed below.

List of porous lead free piezoelectric ceramics and their applications.

TABLE I

\begin{tabular}{|c|c|c|c|c|}
\hline Author & $\begin{array}{c}\text { Porous lead free } \\
\text { material with PFA's }\end{array}$ & Applications & Method & Ref. \\
\hline $\begin{array}{l}\text { Qi Wang, } \\
\text { Qiang Chen, et al. (2008) }\end{array}$ & $\begin{array}{l}\left(\mathrm{Li}_{0.06} \mathrm{Na}_{0.5} \mathrm{~K}_{0.44}\right) \mathrm{NbO}_{3}(\mathrm{LNKN}) \\
-\mathrm{AOM} \text { and PMMA }\end{array}$ & bone substitute & pore-forming method & {$[96]$} \\
\hline $\begin{array}{l}\text { Qi Wang, } \\
\text { Xinmin Chen, et al. (2008) }\end{array}$ & $\begin{array}{l}\left(\mathrm{Li}_{0.06} \mathrm{Na}_{0.5} \mathrm{~K}_{0.44}\right) \mathrm{NbO}_{3}(\mathrm{LNKN}) \\
-\mathrm{AOM} \text { and PMMA }\end{array}$ & bone substitute & $\begin{array}{l}\text { pore-forming method } \\
\text { with modified } \\
\text { polarizing method }\end{array}$ & {$[95]$} \\
\hline $\begin{array}{l}\text { Qi Wang, } \\
\text { Jun Yang, et al. (2009) }\end{array}$ & $\begin{array}{l}\left(\mathrm{Li}_{0.06} \mathrm{Na}_{0.5} \mathrm{~K}_{0.44}\right) \mathrm{NbO}_{3}(\mathrm{LNKN}) \\
\text { - } \mathrm{AOM} \text { and PMMA }\end{array}$ & bone substitute & $\begin{array}{l}\text { pore forming method } \\
\text { with cold isostatic pressing }\end{array}$ & {$[97]$} \\
\hline $\begin{array}{l}\text { Haibo Zhang, } \\
\text { Shenglin Jiang, } \\
\text { Koji Kajiyoshi (2010) }\end{array}$ & $\begin{array}{l}\mathrm{Bi}_{0.5}\left(\mathrm{Na}_{0.82} \mathrm{~K}_{0.18}\right)_{0.5} \mathrm{TiO}(\mathrm{NKBT}) \\
\text { - organic vehicle } \\
\text { [binder (ethyl cellulose), } \\
\text { a solvent ( } \alpha \text {-terpineol), } \\
\text { a plasticizer (polyethylene glycol), } \\
\text { and a dispersing agent } \\
\text { (butoxyethoxyethyl acetate)] }\end{array}$ & $\begin{array}{l}\text { pyroelectric } \\
\text { and piezoelectric } \\
\text { applications } \\
\text { for HFOM }\end{array}$ & $\begin{array}{l}\text { solid state along } \\
\text { with emulsion method }\end{array}$ & {$[98]$} \\
\hline $\begin{array}{l}\text { S. Wada, } \\
\text { Y. Mase, et al. (2011) }\end{array}$ & $\begin{array}{l}\text { porous potassium niobate } \\
\left(\mathrm{KNbO}_{3}, \mathrm{KN}\right) \text { - carbon black }\end{array}$ & $\begin{array}{l}\text { stress sensor } \\
\text { application }\end{array}$ & $\begin{array}{l}\text { conventional } \\
\text { sintering method }\end{array}$ & {$[91]$} \\
\hline $\begin{array}{l}\text { Xiang Wang, Jin-Hong Li, } \\
\text { Hongyao Zhang, } \\
\text { Wei-Min Guan (2014) }\end{array}$ & barium strontium titanate ceramics & $\begin{array}{l}\text { tunable microwave } \\
\text { devices }\end{array}$ & $\begin{array}{l}\text { particle-stabilized } \\
\text { emulsions }\end{array}$ & {$[99]$} \\
\hline $\begin{array}{l}\text { J.I. Roscow, J. Taylor, } \\
\text { C.R. Bowen (2016) }\end{array}$ & $\begin{array}{l}\text { barium titanate }\left(\mathrm{BaTiO}_{3}\right) \\
\text { — polyethylene glycol }\end{array}$ & energy harvester & $\begin{array}{l}\text { burned out polymer } \\
\text { spheres (BURPS) method }\end{array}$ & {$[100]$} \\
\hline
\end{tabular}




\subsection{Energy harvester}

Generation of energy from surrounding environment such as ambient temperature, vibrations or air flow is termed as "energy harvesting". Energy harvesters made of piezoelectric materials convert vibrations into electric energy used for replacement or prolonging the lifespan of batteries which are used to power a range of lowpower electronic devices, such as wireless sensor, etc. [87]. Over the past two decades many examples of potential applications for piezoelectric harvesters have arisen in the form of concepts and prototypes to convert mechanical vibrations into useful electrical energy. It was shown that the lead free porous piezoelectric ceramics are characterized by very high power efficiency. Lead free porous piezoelectric ceramics $\left(\mathrm{BaTiO}_{3}\right)$ with tailored porosity showed significant increase in the energy harvesting figure of merit with a maximum of $2.85 \mathrm{pm}^{2} / \mathrm{N}$ when compared with $\gg 1.0 \mathrm{pm}^{2} / \mathrm{N}$ for the dense material. This energy harvesting FOM values revealed that the piezoelectric material provides an effective route to improve the vibration energy harvesting capacity by introducing porosity. Porous ceramics with fine and low relative porosities provide $1.5-2$ times higher power efficiency than the dense hot-pressed ceramics and can be used as piezoelectric generators. High levels of porosity in the material leads to a significant reduction in permittivity, as well as reducing the volume specific heat capacity which is of interest for piezoelectric ceramic energy harvesting [88]. These results show that using porous material to optimize the distribution of piezoelectric material can harvest more energy than a non-porous material.

\subsection{Sensors}

In sensor and actuator technologies, piezoelectric materials are used for their ability to couple electrical and mechanical displacements, response to an applied mechanical stress, or mechanical strain in response to an applied electric field [89]. Lead free porous piezoelectric ceramics have been extensively utilized for a host of sensor and actuator applications due to their low density, improved hydrostatic figure of merit (HFOM), and coupling with biological tissue or water. The development of new sensing materials with high sensing capabilities is proceeding at an unprecedented rate in process industries, agriculture, medicine, and many other areas. Some of the trend setting sensors are humidity sensors, stress sensors, tactile sensors, etc. These sensors require porous ceramic body for the adsorption of water molecule to improve the electrical conductivity of the surface. Porous lead free barium titanate ceramics were prepared using different kinds of pore-forming agents (PFAs) and were fabricated for positive temperature coefficient of resistance (PTCR) and humidity/gas sensing applications. The porous microstructure of $\mathrm{BTiO}_{3}$ seemed to improve PTCR effect due to oxidation and absorption of oxygen on the grain boundaries, as porous ceramics are more favorable to the formation surface of acceptor states compared to dense ceramics. Thus a porous structure is needed for PTCR properties. By varying different
PFAs the porosity of $\mathrm{BTiO}_{3}$ seemed to improve, which in turn led to humidity or reduced gas sensitivity of barium titanate based ceramics [90]. The relationship between the porosity and piezoelectric properties of lead free potassium niobate and porous potassium niobate with carbon black revealed that, with increasing porosity, piezoelectric $g_{33}$ constant increased significantly, which suggested that porous ceramics were effective for stress sensor application [91].

\subsection{Transducers and hydrophones}

Lead free porous piezoelectric materials are of great interest for low frequency hydrophones: seismic, biologic, military, underwater communication, i.e. which converts mechanical energy of sound waves into electric energy (hydrophones, microphones) and transducers such as an acoustic transducer: echosounders, sonar systems, fish-finders, seabed mapping which converts electric energy into sound waves (transmitters, loudspeakers). Porous piezoelectric materials are used in transducers for their high hydrostatic figures of merit and low sound velocity. These properties help in reducing acoustic impedance and enhanced coupling with water or biological tissue. In hydrophones the most important parameters are acoustic impedance and hydrostatic figureof-merit. In porous piezoelectric ceramic hydrostatic conditions are raised during detection of low frequency signals, as the acoustic wavelength is larger than the material/device and because of this the device lies within the particular designed frequency. In these applications, the acoustic impedance and permittivity are significantly reduced by the introduction of pores in the ceramic matrix as the pores are filled with air. However, by the introduction of air the piezoelectric voltage coefficients is increased. It has also been reported that porous materials potentially offer a high signal to noise ratio for a given volume of material used hydrophone application [92].

\subsection{Bone substitute}

Lead free piezoelectric materials are being significantly used for repairing bone defects on account of their stable piezoelectricity and biocompatibility [93]. Till date only dense counterparts were used for bone substitute, the idea of a porous lead-free piezoelectric ceramic for wettability favorable for nutrient exchange and osseointegration has broadened the scope for porous ceramics [94]. Lead-free $\mathrm{Li}-\mathrm{Na}-\mathrm{K}, 3-3$ porous piezoelectric ceramics were synthesized for potential usage as bone substitute using PMMA and ammonium oxalate monohydrate (AOM) as PFA's. The processed samples showed biological compatibility, i.e. wettability nature same as hydroxyapatite and interconnected pores apt for cell infiltration. In comparison, AOM derived ceramics showed the best pore size and structures, and relatively good piezoelectric properties implying a promising piezoelectric composite used as bone substitute [95, 96]. Work on porous lead free piezoelectric are being less reported. 


\section{Conclusion}

Porous piezoelectric materials are of significant interest due to their wide applications in lightweight structural materials, thermal insulation, and biomaterials. The introduction of porosity within a tailored structure gives porous ceramics many intrinsic properties such as low mass, high permeability, high surface area, low specific heat, and low thermal conductivity. Porous lead based piezoelectric structures were widely used as these materials are of particular interest and technological importance. Due to the well-known toxicity of lead, it is a highly relevant task to find environmentally sound alternatives to PZT and other lead-based piezoelectric ceramic materials. Therefore, lead free materials are being used nowadays as it is environmentally friendly material which offers a HFOM, lower sound velocity reduced acoustic impedance, and enhanced coupling with water or biological tissue. An outline of lead free materials and their importance is reviewed in this work. Various synthesis and processing methods of porous ceramics have been outlined here. Some of the important aspects of porous piezoelectric composites and their properties influenced by porosity configuration have also been deliberated here. As porous piezoelectric ceramic has been a trend setting functional material, various applications of it has also been mentioned.

\section{Acknowledgments}

This research did not receive any specific grant from funding agencies in the public, commercial, or not-for-profit sectors.

\section{References}

[1] T.L. Jordan, Z. Ounaies, Piezoelectric Ceramics Characterization, NASA/CR-2001-211225 ICASE Report No. 2001-28, 2001.

[2] S.S. Chiang, M.Sc. Thesis, Berkeley National Laboratory, Lawrence (CA) 1978.

[3] J.S. Harrison, Z. Ounaies, Piezoelectric Polymers, NASA/CR-2001-211422 ICASE Report No. 2001-43, 2001.

[4] I. Takeuchi, F. Shigehiro, M. Murakami, S.H. Lim, D. Kan, U.S. Patent 8,179,025 B1, May 15, 2012 ..

[5] B. Jaffe, W.R. Cook, H. Jaffe, Piezoelectric Ceramics, Academic Press, London 1971.

[6] Ferroperm Piezoceramics, High Quality Components and Materials for the Electronic Industry.

[7] G. Goodman, in: Ceramic Materials for Electronics - Processing, Properties and Applications, Ed. R.C. Buchanan, Marcel Dekker, New York 1986, p. 131.

[8] Cheng Ma, Hanzheng Guo, S.P. Beckman, X. Tan, Phys. Rev. Lett. 109, 1 (2012).

[9] M. Ahart, M. Somayazulu, R.E. Cohen, P. Ganesh, P. Dera, M.K. Mao, R.J. Hemley, Y. Ren, P. Liermann, Z.U. Wu, Nature 451, 545 (2008).
[10] H.P. Monner, in: Proc. Smart Materials for Active Noise and Vibration Reduction: Novem - Noise and Vibration: Emerging Methods, Saint-Raphaël (France) 2005.

[11] R. Guo, L.E. Cross, S.E. Park, B. Noheda, D.E. Cox, G. Shirane, Phys. Rev. Lett. 84, 5423 (2000).

[12] R. Dahiya, M. Valle, in: Robotic Tactile Sensing, Springer, Netherlands 2013, p. 79.

[13] M.S. Vijaya, in: Piezoelectric Materials and Devices, CRC Press, Taylor\& Francis Group, New York 2013 p. 18 , Ch. 2.

[14] APC International, Piezoelectric Constants USA 2016.

[15] Piezo.com, Terminology, Glossary \& Symbol Usage, USA 2011.

[16] J. Rodel, W. Jo, K.T.P. Seifert, E.M. Anton, T. Granzow, D. Damjanovic, J. Am. Ceram. Soc. 92, 1153 (2009).

[17] D.L. Polla, L.F. Francis, Ann. Rev. Mater. Sci. 28, 563 (1998).

[18] P.K. Panda, J. Mater. Sci. 44, 5049 (2009).

[19] J. Rodel, A.B.N. Kounga, M. Weissenberger-Eibl, D. Koch, A. Bierwisch, W. Rossner, M.J. Hoffmann, R. Danzer, G. Schneider, J. Eur. Ceram. Soc. 29, 1549 (2008).

[20] P. Kumari, R. Rai, S. Sharma, M. Shandilya, A. Tiwari, Adv. Mater. Lett. 6, 453 (2015).

[21] J. Rodel, K.G. Webber, R. Dittmer, W. Jo, M. Kimura, D. Damjanovic, J. Eur. Ceram. Soc. 35, 1659 (2015).

[22] Y.Q. Lu, Y.X. Li, J. Adv. Dielectr. 1, 269 (2011).

[23] T.R. Shrout, S.J. Zhang, J. Electroceram. 19, 113 (2007).

[24] T. Karaki, K. Yan, T. Miyamoto, M. Adachi, Jpn. J. Appl. Phys. 46, 4 (2007).

[25] A.R. von Hippel, Rev. Mod. Phys. 22, 221 (1950).

[26] D.E. Rase, R. Roy, J. Am. Ceram. Soc. 38, 102 (1955).

[27] L. Simon-Seveyrat, A. Hajjaji, Y. Emziane, B. Guiffard, D. Guyomar, Ceram. Int. 33, 35 (2007).

[28] Sonia, R.K. Patel, P. Kumar, C. Prakash, D.K. Agrawal, Ceram. Int. 38, 1585 (2012).

[29] D. Berlincourt, H. Jaffe, Phys. Rev. 111, 143 (1958).

[30] "Directive 2002/95/EC of the European Parliament and of the Council of 27 January 2003 on the restriction of the use of certain hazardous substances in electrical and electronic equipment", , L37, 19 (2003).

[31] T. Takenaka, K. Maruyama, K. Sakata, Jpn. J. Appl. Phys. 30, 2236 (1991).

[32] A. Sasaki, T. Chiba, Y. Mamiya, E. Otsuki, Jpn. J. Appl. Phys. 38, 5564 (1999).

[33] X. Wang, H. Chan, C. Choy, Appl. Phys. A 80, 333 (2005).

[34] Y. Hiruma, H. Nagata, T. Takenaka, J. Appl. Phys. 105, 084112 (2009).

[35] W. Chen, Y. Li, Q. Xu, J. Zhou, J. Electroceram. 15, 229 (2005).

[36] Y. Hiruma, H. Nagata, T. Takenaka, Jpn. J. Appl. Phys. 46, 1081 (2007). 
[37] W. Liu, X. Ren, Phys. Rev. Lett. 103, 257620 (2009).

[38] G. Shirane, R. Newnham, R. Pepinsky, Phys. Rev. 96, 581 (1954).

[39] S. Marselli, V. Pavia, C. Galassi, E. Roncari, F. Craciun, G. Guidarelli, J. Acoust. Soc. Am. 106 733 (1999).

[40] R.Y. Ting, Ferroelectricity 49, 251 (1983).

[41] S.S. Lopatin, T.G. Lupeiko, Inorg. Mater. 40, 19 (2004).

[42] A. Jain, K.J. Prashanth, A.K. Sharma, A. Jain, P.N. Rashmi, Polym. Eng. Sci. 55, 1589 (2015).

[43] H. Kara, R. Ramesh, R. Stevens, C.R. Bowen, IEEE Trans. Ultrason. Ferroelect. Freq. Contr. 50, 289 (2003).

[44] J. Luyten, S. Mullens, I. Thijs, KONA Powder Part. J. 28, 131 (2010).

[45] D.M. Liu, Key Eng. Mater. 115, 209 (1996).

[46] E.K. Akdogan, M. Allahverdi, A. Safari, IEEE Trans. Ultrason. Ferroelect. Freq. Contr. 52, 746 (2005).

[47] D.A. Hirschfeld, T.K. Li, D.M. Liu, Key Eng. Mater. 115, 65 (1996).

[48] R. Gupta, T.A. Venkatesh, Acta Mater. $\quad \mathbf{5 4}$ 4063 (2006).

[49] E. Roncari, C. Galassi, F. Craciun, C. Capiani, A. Piancastelli, J. Europ. Ceram. Soc. 21, 409 (2001).

[50] I.Y. Guzman, Glass Ceram. 60, 280 (2003).

[51] P. Colombo, J.R. Hellmann, Mater. Res. Innovat. 6, 260 (2002).

[52] H.M. Princen, A.D. Kiss, J. Coll. Interface Sci. 128, 176 (1989).

[53] W.D. Kingery, H.K. Bowen, D.R. Uhlmann, in: Introduction to Ceramics, 2nd ed., Wiley Intersci. Publ. New York 1975.

[54] P. Colombo, Philos. Trans. R. Soc. A 364, 109 (2006).

[55] B. Neirinck, J. Fransaer, O.V.D. Biest, J. Vleugels, J. Europ. Ceram. Soc. 29, 833 (2009).

[56] B. P. Binks, Curr. Opin. Coll. Interface Sci. 7, 21 (2002).

[57] T. Ohji, M. Fukushima, J. Int. Mater. Rev. 57, 115 (2012).

[58] R.E. Newnham, D.P. Skinner, L.E. Cross, Mater. Res. Bull. 13, 525 (1978)

[59] Y. Zhang, L. Chen, J. Zeng, K. Zhou, D. Zhang, Mater. Sci. Eng. C 39, 143 (2014).

[60] R.E. Newnham, G.R. Ruschau, J. Am. Ceram. Soc. 74, 463 (1991)

[61] S.H. Lee, S.H. Jun, H.E. Kim, Y.H. Koh, J. Am. Ceram. Soc. 91, 1912 (2008).

[62] T. Xu, C.A. Wang, Mater. Des. 91, 242 (2016).

[63] T. Fukasawa, M. Ando, T. Ohji, S. Kanzaki, J. Am. Ceram. Soc. 84, 230 (2001).

[64] S. Deville, E. Saiz, R.K. Nalla, A.P. Tomsia, Science 311, 515 (2006)

[65] K. Araki, J.W. Halloran, J. Am. Ceram. Soc. 88 1108 (2005)

[66] J.H. Song, Y.H. Koh, H.E. Kim, L.H. Li, H.J. Bahn, J. Am. Ceram. Soc. 89, 2649 (2006).
[67] Y.H. Koh, J.H. Song, E.J. Lee, H.E. Kim, J. Am. Ceram. Soc. 89, 3089 (2006).

[68] S.W. Sofie, F. Dogan, J. Am. Ceram. Soc. 84, 1459 (2001).

[69] J.I. Roscow, V.Y. Topolov, C.R. Bowen, J. Taylor, A.E. Panich, Sci. Technol. Adv. Mater. 17, 769 (2016).

[70] C.R. Bowen, A. Perry, A.C.F. Lewis, H. Kara, J. Europ. Ceram. Soc. 24, 541 (2004).

[71] B.P. Kumar, H.H. Kumar, D.K. Kharat, J. Mater. Sci. Mater. Electron. 16, 681 (2005).

[72] A.N. Rybyanets, Ferroelectricity 419, 90 (2011).

[73] A. Sanson, P. Pinasco, E. Roncari, J. Europ. Ceram. Soc. 28, 1221 (2008)

[74] A.R. Studart, U.T. Gonzenbach, E. Tervoort, L.J. Gauckler, J. Am. Ceram. Soc. 89, 1771 (2006).

[75] P. Sepulveda, Am. Ceram. Soc. Bull. 76, 61 (1997).

[76] D. Guo, K. Cai, L. Li, Z. Gui, J. Europ. Ceram. Soc. 23, 1131 (2003).

[77] F. Levassort, E. Filoux, M. Lethiecq, R. Lou-Moller, E. Ringgaard, A. Nowicki, in: Proc. 2006 IEEE Ultrasonics Symp., Vancouver 2006, p. 2397.

[78] B.H. Kim, J.W. Moon, J.Y. Lee, Y.K. Choi, J. Ceram. Soc. Jpn. 107, 115 (1999).

[79] W. Liu, J. Xu, R. Lv, Y. Wang, H. Xu, J. Yang, Ceram. Int. 40, 2005 (2014).

[80] M. Niino, T. Hirai, R. Watanabe, J. Jpn. Soc. Compos. Mater. 13, 257 (1987).

[81] W. Wersing, K. Lubitz, J. Mohaupt, Ferroelectricity 68, 77 (1986).

[82] T. Zeng, X.L. Dong, S.T. Chen, H. Yang, Ceram. Int. 33, 395 (2007).

[83] A.N. Rybyanets, IEEE Trans. Ultrason. Ferroelect. Freq. Contr. 58, 1492 (2011).

[84] T. Arai, K. Ayusawa, H. Sato, T. Miyata, K. Kawamura, K. Kobayashi, Jpn. J. Appl. Phys. 30, 2253 (1991).

[85] S. Geis, J. Fricke, P. Lobmann, J. Europ. Ceram. Soc. 22, 1155 (2002).

[86] K. Boumchedda, M. Hamadi, G. Fantozzi, J. Europ. Ceram. Soc. 27, 4169 (2007).

[87] C.R. Bowen, H.A., Kim, P.M. Weaver, S. Dunn, Energy Environ. Sci. 7, 25 (2013)

[88] J.I. Roscow, J. Taylor, C.R. Bowen, Ferroelectricity 498, 40 (2016).

[89] N. Setter, in: Piezoelectric Materials in Devices, Ed. N. Setter, Ceramics Laboratory EPFL, Lausanne 2002 , p. 1.

[90] B. Ertug, in: Powder Metallurgy Ions, Ed. K. Kondoh, InTech, Croatia, 2012, p. 73

[91] S. Wada, Y. Mase, S. Shimizu, K. Maeda, I. Fujii, K. Nakashima, P. Pulpan, N. Miyajima, Key Eng. Mater. 485, 61 (2011)

[92] Tao Zeng, Xian Lin Dong, Heng Chen, Yong Lin Wang, Mater. Sci. Eng. B 131, 181 (2006).

[93] J. Feng, H. Yuan, X. Zhang, Biomaterials 18, 1531 (1997).

[94] Yan Zhang, Liangjian Chen, Jing Zeng, Kechao Zhou, Dou Zhang, Mater. Sci. Eng. C 39, 143 (2014). 
[95] Qi Wang, Xinmin Chen, Jianguo Zhu, B. W. Darvell, Zhi-qing Chena, Mater. Lett. 62, 3506 (2008).

[96] Qi Wang, Qiang Chen, Jianguo Zhu, Chunpeng Huang, B.W. Darvell, Zhi-qing Chen, Mater. Chem. Phys. 109, 488 (2008)

[97] Qi Wang, Jun Yang, Wu Zhang, Roxanne Khoie, Yi-ming Li, Jian-guo Zhu, Zhi-qing Chen, Int. J. Oral Sci. 1, 99 (2009).
[98] Haibo Zhang, Shenglin Jiang, Koji Kajiyoshi, J. Am. Ceram. Soc. 93, 1957 (2010).

[99] Xiang Wang, Jin-hong Lin, Hong-yao Zhang, Wei-min Guan, Ceram. Int. 40, 10401 (2014).

[100] G. Martinez-Ayuso, M.I. Friswell, S. Adhikari, H. Haddad Khodaparast, C.A. Featherston, in: Proc. 27th Int. Conf. on Noise and Vibration Engineering (ISMA 2016), Leuven (Belgium), 2016. 